\title{
Validated UV-Spectrophotometric Method for the Simultaneous Estimation of Pyridoxine Hydrochloride and Doxylamine Succinate in Bulk and in Pharmaceutical Dosage form
}

Sangeetha Premkumara, Anandkumar Karunakaran,, , Vasanthi Murugesana, Jambulingam Munusamy ${ }^{a}$, Ramesh Jayaprakasha, Raja Murugesan ${ }^{b}$

\begin{tabular}{|c|c|}
\hline ART I C L E I NFO & A B S T R A C T \\
\hline $\begin{array}{l}\text { K E Y W O R D S } \\
\text { Pyridoxine Hydrochloride } \\
\text { Doxylamine Succinate } \\
\text { Absorbance correction method } \\
\text { Validation }\end{array}$ & $\begin{array}{l}\text { A new, simple, accurate, and sensitive UV - Spectrophotometric absorbance } \\
\text { correction method has been developed for simultaneous determination of } \\
\text { Pyridoxine Hydrochloride and Doxylamine Succinate in bulk and in } \\
\text { combined tablet dosage form using distilled water as a solvent. The } \\
\text { wavelengths selected for the analysis were } 260 \mathrm{~nm} \text { and } 324 \mathrm{~nm} \text {. Both } \\
\text { Pyridoxine hydrochloride and Doxylamine Succinate were linear over the } \\
\text { concentration range of } 5-40 \mu \mathrm{g} / \mathrm{mL} \text { and } 10-60 \mu \mathrm{g} / \mathrm{mL} \text { of Doxylamine } \\
\text { Succinate and Pyridoxine hydrochloride, respectively. The percentage } \\
\text { recovery was found to be in the range of } 99.15-100.71 \% \text { for Pyridoxine } \\
\text { Hydrochloride and } 99.30 \text { - } 101.99 \% \text { for Doxylamine Succinate. The } \% \text { RSD } \\
\text { for recovery studies was found to be } 0.5484 \text { and } 0.9071 \text { for Pyridoxine } \\
\text { hydrochloride and Doxylamine Succinate, respectively. The low } \% \text { RSD of } \\
\text { recovery studies indicated that there is no interference due to excipients } \\
\text { used in formulation. The amount of Pyridoxine hydrochloride and } \\
\text { Doxylamine succinate was found to be } 100.92 \% \pm 0.6961 \text { and } 101.05 \% \pm \\
0.7965 \text {. Optical characteristics like slope, intercept, molar absorptivity, } \\
\text { correlation coefficient, LOD and LOQ were calculated. The developed } \\
\text { method was validated statistically by recovery studies as per ICH } \\
\text { guidelines. The } \% \text { RSD value was found to be less than } 2 \text {. Thus the proposed } \\
\text { method was simple, precise, rapid and accurate and can be successfully } \\
\text { applied for routine quality control analysis of simultaneous determination } \\
\text { of Pyridoxine Hydrochloride and Doxylamine Succinate in bulk and in } \\
\text { combined tablet dosage form. }\end{array}$ \\
\hline
\end{tabular}

GRA P H I C A L A B S T RACT

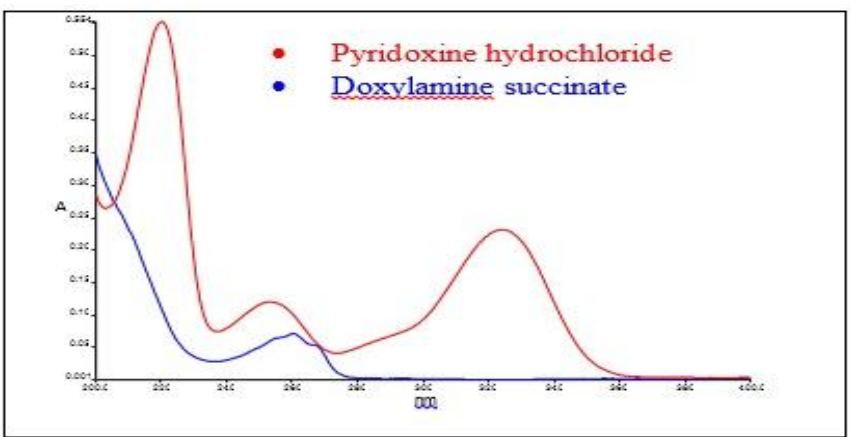

* Corresponding author's E-mail address: anandanalysis@gmail.com, Tel.: +919443454675

a Department of Pharmaceutical Analysis, Swamy Vivekanandha College of Pharmacy, Tiruchengode - 637

205, Namakkal (Dt), Tamil Nadu, India

b Department of Pharmaceutics, JSS College of Pharmacy, "Rockland's", Ooty, Tami Nadu, India 


\section{Introduction}

Pyridoxine Hydrochloride (PYRI), chemically it is 5-hydroxyl-6methyl pyridine 3, 4 dimethanol [1] (Figure 1). Pyridoxine is converted in erythrocytes to pyridoxal phosphate and to a lesser extent pyridoxamine phosphate which act as coenzymes for various metabolic functions affecting protein, carbohydrate, and lipid utilization [2]. It is official in IP [3], BP [4] and USP [5].

Doxylamine Succinate (DOXY), chemically it is dimethyl (\{2-[1-phenyl-1-(pyridin-2-yl) ethoxy] ethyl\}) amine (Figure 2). Doxylamine Succinate is an antihistamine, used to relieve symptoms of allergy, hay fever, and the common cold. This effect helps to relieve allergy, cold symptoms such as
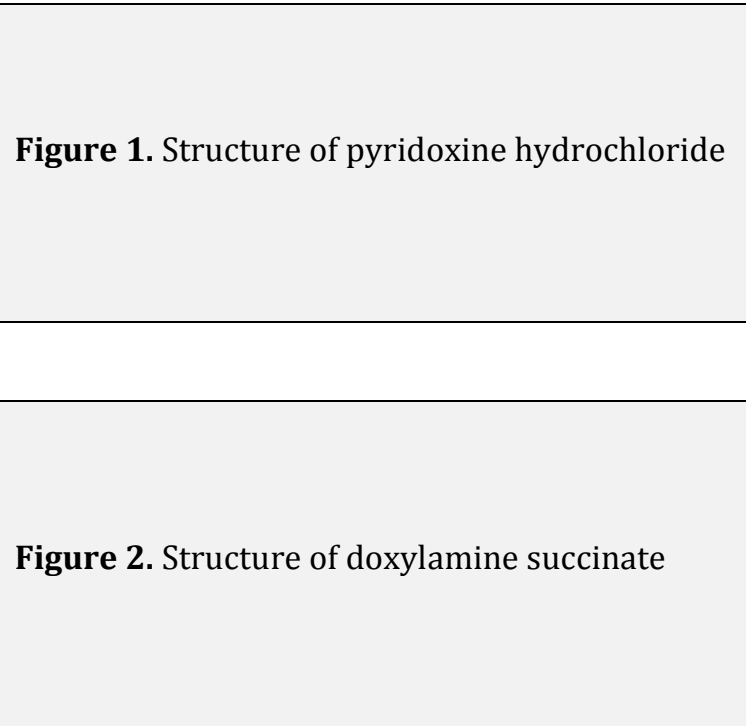

watery eyes, runny nose, and sneezing [6, 7]. Also used in the combination with Vitamin B6 (pyridoxine) to prevent morning sickness in pregnant women [8]. The combined dosage forms of DOXY and PYRI are available in the market for the treatment of vomiting during pregnancy. It is official in BP [9] and USP [10].

Literature survey revealed that numbers of RP-HPLC methods are available for DOXY in combination with other drugs [11-14] and also PYRI in combination with other drugs [15-17]. RP-HPLC method was also reported for the simultaneous estimation of DOXY and PYRI in combination [18-20]. UV Spectrophotometric method like simultaneous equation method [21-23] and First derivative Spectrophotometry [24] were reported.
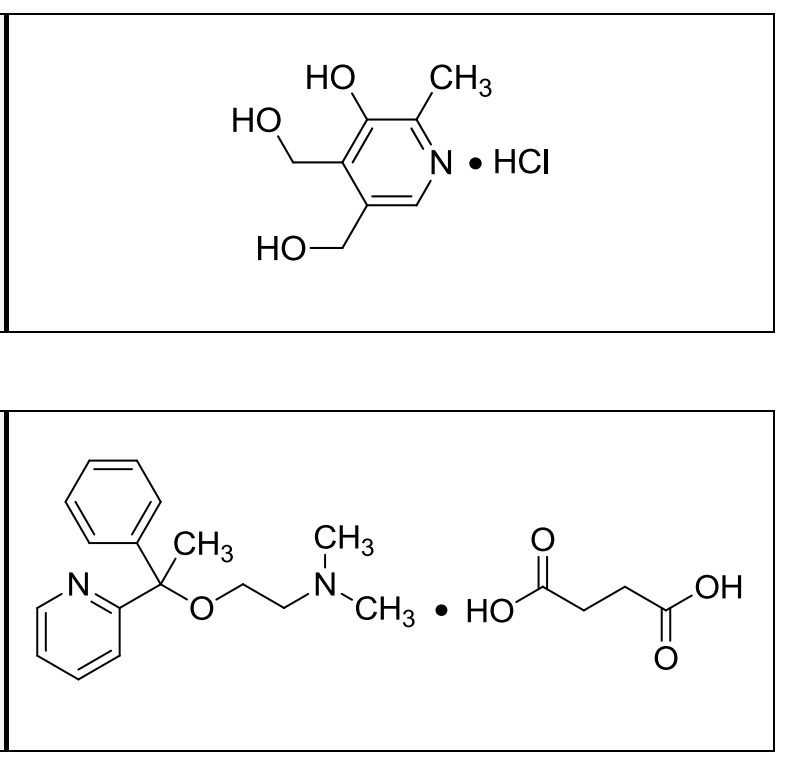
The present study aims to develop a simple, sensitive, accurate, precise, reproducible and rapid UV Spectrophotometric method for the estimation of DOXY and PYRI in bulk and in combined tablet dosage form by using absorbance correction method.

\section{Materials and methods}

\section{Apparatus}

A Perkin Elmer model Lambda 25 double beam UV-Visible spectrophotometer with spectral width of $2 \mathrm{~nm}$, wavelength accuracy of $0.5 \mathrm{~nm}$ and a pair of $10 \mathrm{~mm}$ matched quartz cell were used to measure absorbance of all the solutions. A Shimadzu AUX 220 electronic balance was used in the study.

\section{Reagents and Materials}

PYRI and DOXY bulk powder was kindly gifted by Sai Mirra Inno pharm Pvt Ltd, Chennai, India. The commercial fixed dose combination of Doxinate tablet containing $10 \mathrm{mg}$ of Pyridoxine Hydrochloride and 10 mg of Doxylamine Succinate was procured from the local market. Calibrated glass wares were employed throughout the work.

\section{Experimental condition}

According to the solubility characteristics, the common solvent for the two drugs was found to be distilled water. Hence the stock solution was prepared using distilled water. Preparation of standard stock solution
$100 \mathrm{mg}$ of PYRI and $100 \mathrm{mg}$ of DOXY were accurately weighed and transferred in to $100 \mathrm{ml}$ volumetric flasks separately. Dissolved in distilled water and made up to the volume to $100 \mathrm{ml}$ with the same. These solutions were observed to contain $1 \mathrm{mg} /$ $\mathrm{mL}$ of both PYRI and DOXY, respectively.

\section{Study of spectral and linearity characteristics}

The standard stock solutions of PYRI and DOXY were further diluted with distilled water to get the concentration of $10 \mu \mathrm{g} / \mathrm{mL}$ of each and the solutions were scanned between the range $200-400 \mathrm{~nm}$ in $1 \mathrm{~cm}$ cell against distilled water as blank. The overlain spectra were recorded. From the overlain spectrum of PYRI and DOXY, it was observed that DOXY have zero absorbance at $324 \mathrm{~nm}$, whereas PYRI has substantial absorbance. Hence, PYRI was estimated directly at 324 $\mathrm{nm}$ without interference of DOXY. At 260 $\mathrm{nm}$, these two drugs were showed the absorbance. To estimate the amount of DOXY, the absorbance of PYRI were corrected for interference at $260 \mathrm{~nm}$ by using their absorptivity values.

\section{Preparation of calibration graph}

The standard stock solution of PYRI (0.5 - 4 $\mathrm{mL}$ ) and DOXY (1 - $6 \mathrm{~mL}$ ) was transferred into a series of $100 \mathrm{ml}$ volumetric flask and made up to the volume with distilled water. The absorbance of different concentration 
solutions were measured at $260 \mathrm{~nm}$ and 324 $\mathrm{nm}$. The calibration curve was constructed by plotting concentration Vs absorbance. PYRI was linear with the concentration range of $5-40 \mu \mathrm{g} / \mathrm{mL}$ at 260 and $324 \mathrm{~nm}$ and DOXY was linear with the concentration range of $10-60 \mu \mathrm{g} / \mathrm{mL}$ at $260 \mathrm{~nm}$.

\section{Analysis of synthetic mixture of DOXY and PYRI}

Different mixtures of the two drugs were prepared by transferring different volumes of PYRI and DOXY from standard stock solutions into $100 \mathrm{~mL}$ volumetric flasks and diluting to volume with distilled water. The concentrations of all the two drugs were determined by measuring the absorbance of the prepared mixtures at $324 \mathrm{~nm}$ and 260 nm. From these absorbance values, the concentrations of PYRI and DOXY were determined by using absorbance correction method.

\section{Analysis of tablet formulation}

Ten tablets were weighed and average weight was found. The tablets were triturated to a fine powder. An accurately weighed quantity of powder equivalent to $100 \mathrm{mg}$ of Pyridoxine Hydrochloride was transferred in to $100 \mathrm{~mL}$ volumetric flask and added a minimum quantity of distilled water to dissolve the substance and made up to the volume with the same. The solution was sonicated for 15 minutes, centrifuged for another 15 minutes at $100 \mathrm{rpm}$ and filtered through the Whatmann filter paper No. 41. From the clear solution, further dilutions were made by diluting $2 \mathrm{~mL}$ into $100 \mathrm{ml}$ with distilled water to obtain 20 $\mu \mathrm{g} / \mathrm{mL}$ solution of PYRI which is also contains $20 \mu \mathrm{g} / \mathrm{mL}$ of DOXY theoretically. The absorbance of sample solution was measured at all selected wavelengths. The content of PYRI and DOXY in sample solution was calculated. This procedure was repeated for six times.

\section{Recovery studies}

\section{Preparation of DOXY and PYRI raw material stock solution}

$400 \mathrm{mg}$ of PYRI and DOXY was accurately weighed and transferred into $10 \mathrm{~mL}$ volumetric flask individually and sufficient distilled water is added to dissolve the substance and made up to the mark with the same. Both the stock solution contains 40 $\mathrm{mg} / \mathrm{mL}$ concentration.

\section{Procedure}

The recovery experiment was done by adding known concentrations of raw material stock solution of PYRI and DOXY to the pre-analyzed formulation. The tablet powder equivalent to $100 \mathrm{mg}$ of PYRI was weighed accurately and added $2 \mathrm{~mL}, 2.5 \mathrm{~mL}$ and $3 \mathrm{~mL}$ of above raw material stock solutions into a series of $100 \mathrm{~mL}$ volumetric flask and dissolved with distilled water and 
sonicated for 15 minutes. The solution was made up to $100 \mathrm{~mL}$ with distilled water and centrifuged for 15 minutes at $2000 \mathrm{rpm}$. The supernatant liquid was filtered through a Whatmann filter paper No.41. $2 \mathrm{ml}$ of the clear solution was transferred into $100 \mathrm{~mL}$ volumetric flask and made up to $100 \mathrm{~mL}$ with distilled water. The absorbance of three replicates was measured at their selected wavelengths. The amount of drug recovered from formulation was calculated. The procedure was repeated for three times for each concentration.

\section{Validation}

The method was validated as per ICH guidelines [25]. The methods were validated with respects to linearity, LOD (Limit of detection), LOQ (Limit of quantitation), precision, accuracy and ruggedness. The validation parameters are explained as given below.

\section{Linearity}

Linearity was checked by diluting standard stock solution at different concentrations. PYRI was linear with the concentration range of $5-40 \mu \mathrm{g} / \mathrm{mL}$ at 260 and $324 \mathrm{~nm}$. DOXY was linear with the concentration range of $10-60 \mu \mathrm{g} / \mathrm{mL}$ at $260 \mathrm{~nm}$. Calibration curves $(n=6)$ were plotted between concentration and absorbance of drugs. Optical parameters such as slope, intercept, molar absorptivity, correlation coefficient,
LOD and LOQ were calculated.

\section{Sensitivity}

The limit of detection (LOD) and limit of quantitation (LOQ) parameters were calculated using the following equations; $\mathrm{LOD}=3.3 \sigma / \mathrm{S}$ and LOQ $=10 \sigma / \mathrm{S}$, where $\sigma$ is standard deviation of $y$ intercept of calibration curve $(n=6)$ and $S$ is slope of regression equation

\section{Precision}

The precision of the method was confirmed by repeatability and intermediate precision. The repeatability was performed by the analysis of formulation was repeated for six times with the same concentration. The amount of each drug present in the tablet formulation was calculated. The \% RSD was calculated. The intermediate precision of the method was confirmed by intraday and inter day analysis i.e. the analysis of formulation was repeated three times in the same day and on three successive days. The amount of drugs was determined and \% RSD also calculated.

\section{Accuracy}

To check the accuracy of the developed method and to study the interference of formulation excipients, analytical recovery experiments were carried out by using standard addition method in three different concentrations viz, $80 \%, 100 \%$ and $120 \%$. From the total amount of drug found, the 
percentage recovery was calculated. This procedure was repeated for three times for each concentration. The \% RSD was calculated.

\section{Ruggedness}

The ruggedness test of analytical assay method is defined as the degree of reproducibility of test results obtained by the analysis of the same samples under a variety of normal test conditions such as different labs, different analysis, different lots of reagents etc. Ruggedness is a measure of reproducibility of test results under normal expected operational conditions from laboratory to laboratory and from analyst to analyst. In present study, determination of DOXY and PYRI were carried out by using different analysts.

\section{Results and discussion}

A simple, precise, accurate and rapid UV Spectrophotometric method was developed for the estimation of DOXY and PYRI in bulk and in formulation by using absorbance correction method. From the solubility data, distilled water was used as a common solvent for the analysis of these drugs. The spectrum of PYRI and DOXY was reported in the wavelength range of $200-400 \mathrm{~nm}$ and overlain. From the overlain spectrum, the wavelengths selected for the analysis were $324 \mathrm{~nm}$ and $260 \mathrm{~nm}$ (Figure 3).

Based upon the spectral characteristics of both the drugs, absorbance correction method was selected for analysis. At $260 \mathrm{~nm}$ both PYRI and DOXY were have marked absorbance. At 324 nm PYRI had absorbance but DOXY is zero. Hence at $324 \mathrm{~nm}$ PYRI could be analyzed without the interference of DOXY. After determining the amount of PYRI at $260 \mathrm{~nm}$ the absorbance of PYRI was corrected to determine the amount of DOXY. Hence these two wavelengths were selected for the simultaneous estimation of PYRI and DOXY in combination without prior separation.

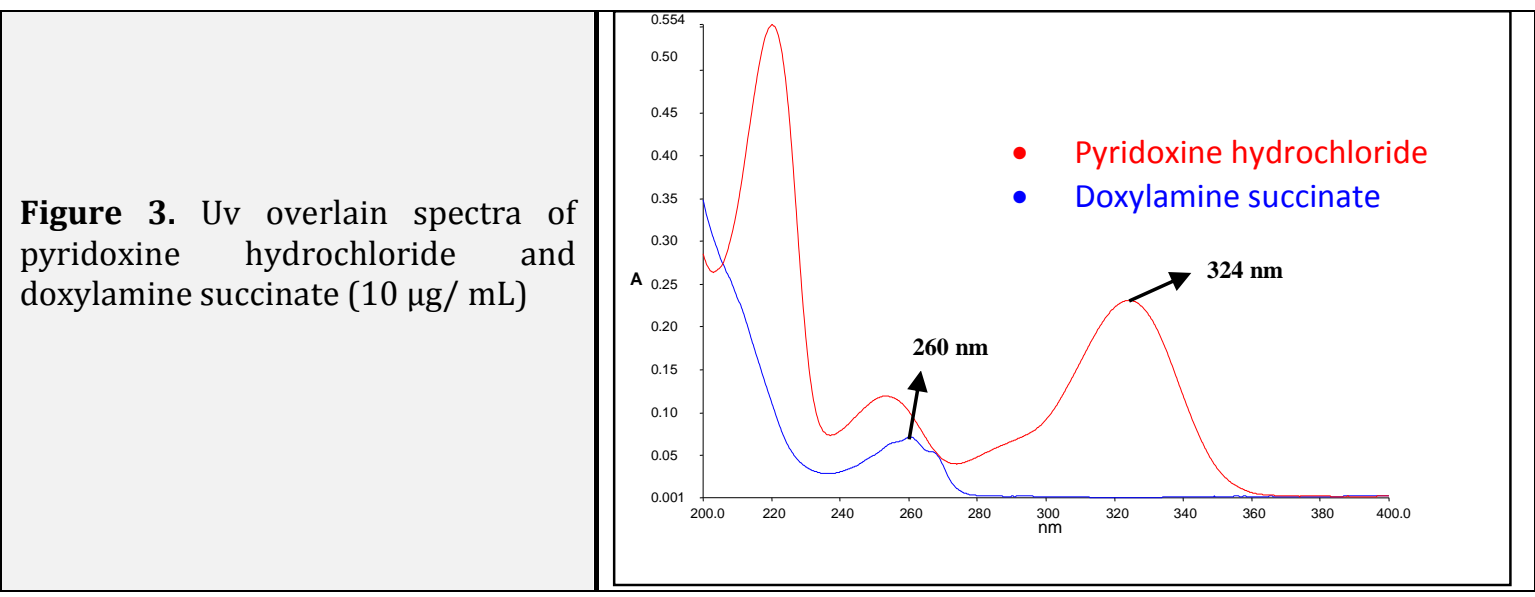


The stability of PYRI and DOXY was studied by measuring the absorbance at different time intervals. It was observed that PYRI was stable up to 6 hours in distilled water and DOXY was stable up to 1 hour 30 minutes in distilled water.

\section{Validation Data of the Proposed Methods}

Beer's law obeyed in the concentration range of $5-40 \mu \mathrm{g} / \mathrm{mL}$ at $324 \mathrm{~nm}$ and $10-60$ $\mu \mathrm{g} / \mathrm{mL}$ at $260 \mathrm{~nm}$ for PYRI and DOXY, respectively. The correlation coefficient values were found to be above 0.999 , which shows that absorbance of all the drugs was linear with concentration. The optical characteristics such as Beer's law limits, correlation Coefficient, slope, intercept, Sandell's sensitivity and molar absorptivity were calculated and are summarized in (Table 1).

The LOD and LOQ were found to be 0.1539 and 0.4664 for PYRI and 0.0318 and 0.0964 for DOXY, respectively. The low values indicated that the sensitivity of the method. To study the mutual interference, if any, in the simultaneous estimation of synthetic mixture containing various proportions of PYRI and DOXY were prepared and the contents were estimated by proposed method. The \% Recovery varied from 100.05 - 101.85\% for PYRI and 99.99 - 102.11\% for DOXY indicating that there is no mutual interference between these two drugs. The result of analysis of synthetic mixture is shown in (Table 2).

The percentage label claim present in tablet formulation was found to be $101.32 \pm 1.2453$ for PYRI and $100.17 \% \pm 0.8898$ for DOXY, respectively. Precision of the method was confirmed by the repeated analysis of formulation for six times. The \% RSD values were found to be 1.2291 for PYRI and 0.8882 for DOXY, respectively.

Table 1. Optical characteristics of pyri and doxy at the selected wavelengths

\begin{tabular}{ccc}
\hline Parameters & Pyridoxine Hydrochloride & Doxylamine Succinate \\
\hline$\lambda \max (\mathrm{nm})$ & $324 \mathrm{~nm}$ & $260 \mathrm{~nm}$ \\
Beer's law limit $(\mu \mathrm{g} / \mathrm{ml})$ & $5-40$ & $10-60$ \\
Sandell's sensitivity & & \\
$\left(\mu \mathrm{g} / \mathrm{cm}^{2} / 0.001 \mathrm{~A} . \mathrm{U}\right)$ & 0.0304 & 0.0980 \\
Molar absorptivity & & \\
$\left(\mathrm{L} \mathrm{mol}^{-1} \mathrm{~cm}^{-1}\right)$ & 6890.0938 & 2792.8950 \\
Correlation coefficient $(\mathrm{r})$ & 0.9999 & 0.9998 \\
Regression equation & & \\
$(\mathrm{y}=\mathrm{mx}+\mathrm{c})$ & $\mathrm{Y}=0.0329 \mathrm{x}+0.0058$ & $\mathrm{Y}=0.0101 \mathrm{x}+0.0013$ \\
Slope $(\mathrm{m})$ & 0.0329 & 0.0101 \\
Intercept $(\mathrm{c})$ & 0.0058 & 0.0013 \\
LOD $(\mu \mathrm{g} / \mathrm{ml})$ & 0.1539 & 0.0318 \\
LOQ $(\mu \mathrm{g} / \mathrm{ml})$ & 0.4664 & 0.0044 \\
Standard error & 0.0068 & \\
\hline
\end{tabular}

*Mean of six observations 
Table 2: Results of analysis of synthetic mixtures

\begin{tabular}{cccccc}
\hline \multicolumn{2}{c}{$\begin{array}{c}\text { Concentration of Pyridoxine } \\
\text { Hydrochloride }(\boldsymbol{\mu g} / \mathbf{m l})\end{array}$} & $\begin{array}{c}\% \\
\text { Recovery }\end{array}$ & \multicolumn{2}{c}{$\begin{array}{c}\text { Concentration of Doxylamine } \\
\text { Succinate }(\boldsymbol{\mu g} / \mathbf{m l})\end{array}$} & $\begin{array}{c}\% \\
\text { Recovery }\end{array}$ \\
\hline \multicolumn{2}{c}{ Theoretical } & Experimental & & Theoretical & Experimental \\
\hline 10 & 9.8728 & 100.05 & 40 & 40.3551 & 101.08 \\
15 & 15.2786 & 101.85 & 35 & 35.3835 & 101.09 \\
20 & 20.1337 & 100.62 & 30 & 30.5584 & 101.85 \\
25 & 25.0522 & 100.20 & 25 & 25.1925 & 100.10 \\
30 & 30.4058 & 101.35 & 20 & 20.2243 & 101.11 \\
35 & 35.5613 & 101.60 & 15 & 15.3194 & 102.11 \\
40 & 40.2989 & 100.74 & 10 & 9.9997 & 99.99 \\
\hline
\end{tabular}

Table 3: Results of analysis of tablet formulation

\begin{tabular}{ccc}
\hline Parameters & Pyridoxine Hydrochloride & Doxylamine Succinate \\
\hline Label Claim $(\mathrm{mg})$ & $10 \mathrm{mg}$ & $10 \mathrm{mg}$ \\
\% Assay* & 101.32 & 100.17 \\
SD & 1.2453 & 0.8898 \\
\% RSD & 1.2291 & 0.8882 \\
\hline
\end{tabular}

*Mean of six observations

The low \% RSD values indicated that both drugs showed good agreement with the label claim ensures the precision of the method were shown in (Table 3).

Further, the precision of the method was confirmed by Intraday and Inter day analysis. The \% RSD values for intraday and inter day analysis was found to be 0.2603 and 1.1609 for DOXY, 0.1891 and 0.19920 for PYRI, respectively. Hence the precision of the method was further confirmed (Table 4).

The developed method was validated for Ruggedness. The analysis of formulation was done by using different analysts. The $\%$ RSD values were found to be less than 2 indicating that the method was more rugged. The results of analysis of intermediate precision and ruggedness are shown in (Table 4).

In order to check the accuracy of the developed method, known quantities of standard drugs of PYRI and DOXY in three different concentrations were added to its pre analyzed sample and analyzed by the developed method. The percentage recovery was found to be in the range of 99.31-100.45\% for PYRI and 99.55$101.49 \%$ for DOXY. The results of recovery studies are shown in (Table 5). The \% RSD values for PYRI and DOXY were found to be 0.5484 and 0.9017 , respectively. The low $\%$ RSD values confirmed that there is no interference due to the excipients used in formulation. This ensures the accuracy of the method. 
Table 4: Intermediate precision and ruggedness of the method

\begin{tabular}{ccc}
\hline Parameters & \multicolumn{2}{c}{ \% Label claim estimated (Mean \pm \% RSD) } \\
& Pyridoxine Hydrochloride & Doxylamine Succinate \\
\hline Intraday Precision $(\mathrm{n}=3)$ & $101.78 \pm 0.1891$ & $100.95 \pm 0.2603$ \\
Inter day Precision $(\mathrm{n}=3)$ & $101.69 \pm 1.9920$ & $99.93 \pm 1.1609$ \\
Different analysts $(\mathrm{n}=6)$ & & \\
Analyst I & $101.64 \pm 0.2673$ & $100.50 \pm 0.3306$ \\
Analyst II & $101.27 \pm 0.1786$ & $100.23 \pm 0.5139$ \\
\hline
\end{tabular}

*Mean of six observations

Table 5. Recovery studies

\begin{tabular}{cccccccc}
\hline Drug & $\begin{array}{c}\text { Amount } \\
\text { present } \\
(\boldsymbol{\mu g} / \mathbf{m L})\end{array}$ & $\begin{array}{c}\text { Amount } \\
\mathbf{a d d e d} \\
(\boldsymbol{\mu} / \mathbf{m L})\end{array}$ & $\begin{array}{c}\text { Amount } \\
\text { found } \\
(\boldsymbol{\mu g} / \mathbf{m L})\end{array}$ & $\begin{array}{c}\text { Amount } \\
\text { recovered } \\
(\boldsymbol{\mu} \mathbf{g} / \mathbf{m L})\end{array}$ & $\begin{array}{c}\text { \% } \\
\text { Recovery* }\end{array}$ & SD & \% RSD \\
\hline Pyridoxine & 20.2639 & 16.0759 & 36.4150 & 16.1510 & 100.45 & & \\
Hydrochloride & 20.2639 & 20.1337 & 40.4139 & 20.1500 & 100.07 & 0.5481 & 0.5484 \\
& 20.2639 & 24.2558 & 44.3549 & 24.0910 & 99.31 & & \\
Doxylamine & 20.0350 & 16.2739 & 36.2365 & 16.2015 & 99.55 & & \\
Succinate & 20.0350 & 20.2013 & 40.5393 & 20.5043 & 101.49 & 0.9073 & 0.9017 \\
& 20.0350 & 24.0297 & 44.2580 & 24.2230 & 100.79 & & \\
\hline
\end{tabular}

*Mean of three observations

\section{Conclusion}

From validation, the developed method was found to be simple, rapid, economical, precise, accurate and rugged. Hence the proposed method could be effectively applied for the routine quality control analysis of PYRI and DOXY in bulk and in combined tablet dosage form.

\section{Acknowledgement}

The authors are very much thankful to Dr. G. Murugananthan, Principal, Swamy Vivekanandha college of Pharmacy, Tiruchengode, for his support and also thankful to the management for providing the necessary facilities to carry out the research work successfully.

\section{References}

[1]. J.O. Maryadele, P.E. O'Neil, C.B. Heckelman, K.J.R. Koch, The Merck Index, An encyclopedia of chemicals, drugs and biologicals. $4^{\text {th }}$ Edition. Merck research laboratories division of Merck Co. Inc. Whitehouse Station, NJ, USA., 2006; 4441, 7982.

[2]. Stroev, Biochemistry. MIR Publishers, Perulok, Moscow. 1996; 352.

[3]. The Indian Pharmacopoeia, Volume III, the Indian Pharmacopoeia Commission, India, 2014; p 2600.

[4]. The British Pharmacopoeia. Volume II, British Pharmacopoeia Commission, Elms Lane, London. 2011; 1847. 
[5]. The United States Pharmacopoeia/ The National Formulary. Volume III, The United Stated Pharmacopoeial Convention, Rockville, MD. 2008; 3137.

[6]. A.C. Moffat, D.M Osselton, Brian Widdap, Jo Watts, Clark's Analysis of Drugs and Poisons. Volume II, $4^{\text {th }}$ Edition, Pharmaceutical Press, London. 2011; pp.1309-1311.

[7]. S.C. Sweetman, Martindale. The Complete Drug Reference. Volume A, 37th Edition. Pharmaceutical Press, London. 2011; 2140.

[8]. S.C. Sweetman, Martindale. The Complete Drug Reference. Volume A, 37th Edition. Pharmaceutical Press, London. 2011; 629.

[9]. The British Pharmacopoeia. Volume I, British Pharmacopoeia Commission, Elms Lane, London. 2011; 769.

[10]. The United States Pharmacopoeia/ The National Formulary. Volume II, The United Stated Pharmacopoeial Convention, Rockville, MD. 2008; 2026.

[11]. D. Varasala, S.k. Konidala, Der pharma. Lett., 2015, 7, 112-118.

[12]. P.C.P. Cesar, I.C.S.F. Jardim, Braz. J. Pharm. Sci., 2012, 48, 315-323.

[13]. P. Bhortake, R.S. Lokhande, Int. J. Pharm. Sci. Inven., 2014, 3, 08.

[14]. M. Alagar Raja, M. Samatha, David Banji, K.N.V. Rao, Sujitha, J. Vinod, D. Selva
Kumar, W. J. Pharma and Pharm. Sci., 2013, 2, 5852-5862.

[15]. M.D. Saddam Nawaz, Chromatogr. Res. Int., 2013, 2013, 1.

[16]. S.K. Dhal, R. Sharma, Chem. Anal., 2009, $54,1487-1500$.

[17]. H. Elsadig, K.H. Adam Ramadan AlShdefat, J. Chem. Pharm. Sci., 2015, 8, 238.

[18]. S. Masoom vali, G. Somasekhar, Y. Suresh, S. Haniffer Bee, K. Suresh, Int. J. Chem. Pharm. Sci., 2018, 6, 16.

[19]. B. Praveen kumar, S. Vidhyadhara, T.E.G.K. Murthy, R.L.C. Sasidhar, V. Sri Krishna, Eurasian. J. Anal. Chem., 2017, 12, 459-468.

[20]. P. Giriraj, T. Sivakumar, Chromatogr. Res. Int., 2014, 2014, 1-8.

[21]. A. Pathak, S.J. Rajput, Indian J. Pharma. Sci., 2008, 70, 513-517.

[22]. P. Giriraj, T. Sivakumar, Der Pharma Chem., 2014, 6, 495-501.

[23]. V. Rajani Sekhar, I. Sowkar Baig, R. Amulya, P. Nagarjuna, Int. j. Pharma. Res. Anal., 2014, 4, 139-143.

[24]. K.S. Nataraj ,Y. Severna, G. Venkateswari, Int. J Pharma Pharm. Sci., 2013, 5, 388-390.

[25]. Code Q2R1 ICH Guideline. Text on Validation of Analytical Procedure. ICH guidelines. Geneva, Switzerland, 2015, 1-16. 
How to cite this manuscript: Sangeetha Premkumar, Anandkumar Karunakaran*, Vasanthi Murugesan, Jambulingam Munusamy, Ramesh Jayaprakash, Raja Murugesan, Validated UV-Spectrophotometric Method for the Simultaneous Estimation of Pyridoxine Hydrochloride and Doxylamine Succinate in Bulk and in Pharmaceutical Dosage form, Advanced Journal of Chemistry-Section A (Adv. J. Chem. A), 2019, 2(3), 245-255. 